\title{
SHEAR BOND STRENGTH OF ORTHODONTIC BRACKETS BETWEEN HEALTHY AND MILD FLUOROSED ENAMEL
}

\author{
Mohamed I.Ebrahim*
}

\begin{abstract}
Objective: To evaluate the influence of dental fluorosis on the shear bond strengths of orthodontic brackets bonded to enamel. Materials and methods: Twenty human maxillary central incisors, extracted for periodontal reasons were used. The sample was divided into two experimental groups. Group A with healthy teeth and group B with mild fluorosed teeth. Etching enamel then the adhesives were applied to entire enamel surface then light cured for 10 seconds with LED. The base ceramic orthodontic brackets were filled by nano-filled composite and placed on the tooth and cured by LED for 40 seconds. The specimens were then thermocycled $\left(5-55^{\circ} \mathrm{C}, 500\right.$ cycles $)$ and tested in Lloyd universal testing machine. The recorded values of bond strengths in (MPa) were collected, tabulated and statistically analyzed. One way analysis of variance (ANOVA) and Tukey's tests were used for testing the significance between the means of tested groups which are statistically significant when the $P$ value $\leq 0.05$. Results: The mean shear bond strength of ceramic brackets bonded to non-fluorosed enamel (Group A) was significantly higher than shear bond strength of ceramic brackets bonded to fluorosed enamel (group B).
\end{abstract}

\section{INTRODUCTION}

Dental fluorosis is a developmental tooth enamel lesion resulting from a fluoride overdose and chronic ingestion during early childhood ${ }^{1}$. This condition leads to metabolic changes in ameloblasts, resulting in a poor matrix formation and tooth calcification ${ }^{2}$. The fluorosed enamel is characterized by a hypermineralized outer layer and a hypomineralized and porous sublayer ${ }^{3}$.

Phosphoric acid is used in the form of a solution or gel etches at a concentration of $37 \%$. The acid is applied on enamel surface thus cleanses the surface and improves the wettability of enamel by the resin. It also causes selective dissolution of enamel rods. The acid removes calcium salts from enamel, thus increases the size and number of micro spaces present in the enamel surface which is normally porous. When the resin is applied on such etched enamel surface, it can penetrate into micro spaces or irregularities, thus producing "resin tag" (finger like projections) with subsequent increase in bond strength and reduction of marginal staining and discoloration ${ }^{4}$.

The adhesion to enamel of fluorosed teeth may be compromised, due to the etching procedure that has been proven to be less effective in these hypermineralized surfaces ${ }^{5}$. Some authors advocate the increase of etching time in order to overcome suchlimitation ${ }^{6}$.

Orthodontic treatment with fixed appliances need adequate bond between brackets and tooth enamel, and may be a clinical challenge in endemic fluorosis regions. If bond strength values are too low, earlier debonding of brackets may occur as a result of normal clinical stress lead to delay treatment ${ }^{7}$.

Thermocycling is defined as the in vitro process of subjecting a restoration and tooth to temperature extremes that conform to those found in the oral cavity. Thermocycling considered cycling regimes employing short dwell time to be more realistic clinically. Cyclic loading application was made to simulate clinical occlusal stress condition in oral cavity ${ }^{8}$.

\footnotetext{
* Assistant Professor of Dental Biomaterials, Faculty of Dental Medicine Al Azhar University, Cairo (Boys).
} 
Measurement of shear bond strength is the most commonly used laboratory method to evaluate the performance of orthodontic bonding systems and a variety of techniques have been applied for shear bond strength measurements ${ }^{9}$. However, the lack of standardization of bond strength testing and the large distribution of results often prevent confident conclusions from being drawn ${ }^{10}$. Shear tests typically involve a combination of shear and peel forces because force is applied at a distance from the bonding interface ${ }^{11}$.

The purpose of this study was to evaluate the influence of dental fluorosis on the shear bond strengths of orthodontic ceramic brackets bonded to enamel.

\section{MATERIALS AND METHODS}

An in vitro study was conducted to shear bond strength of orthodontic brackets between healthy and fluorosed enamel.

Twenty extracted human maxillary central incisors, extracted for periodontal reasons were used.

Teeth collected were stored in $0.5 \%$ chloramine solution at $4^{\circ} \mathrm{C}$ for a week followed by immersion in distilled water at $4^{\circ} \mathrm{C}$ until bonding procedures. Before bonding, buccal surfaces were cleaned with a mixture of water and non-fluoride pumice, thoroughly rinsed with water spray and air-dried.

The sample was divided into two experimental groups (10 each). Group A with healthy teeth and group B with mild fluorosed teeth.

Each enamel was acid etched using 37\% phosphoric acid gel* for 30 seconds. Then the enamel was rinsed with water spray and dried with oil free stream for 5 seconds. Apply primer on etched enamel surface by using the applicator brush.

\footnotetext{
* Eco-Etch. Ivoclar vivadent.

**BG-light-LTD, 4002 Plovdiv, 430-490nm, Bulgaria

***LI-189 Li-Cor Inc, Lincoln, NE6804, USA.
}

Remove the excess primer with a dry applicator brush, but leave the surface with a very wet appearance, Then light cured for 10 seconds with light emitting diodes** (LED). The adhesives were applied to the entire enamel surface [Nano-Bond adhesive (Pentron Clinical technologies, USA, lot \# 183421)] then air thinning for 15 seconds. A gentle stream of dry air was applied to disperse the material into a thin, uniform, shiny appearing surface. The adhesive was then light cured for 10 seconds with LED.

The base of ceramic brackets (Crystaline; Tomy, Tokyo, Japan) were filled by nano-filled composite (Artiste Nanocomposite, Pentron Clinical technologies LLc, USA, lot \# 182066-185215) and placed on the tooth and pressed firmly onto the surface. Any excess of the flowable composite resin was removed and the flowable composite resin was cured by LED for 40 seconds with the tip close to the surface as possible $(20 \mathrm{~s}$ from mesial and $20 \mathrm{~s}$ from distal).

Curing radiometer equipment*** used to ensure steady light intensity throughout the polymerization of all specimens.

Teeth were embedded in chemically cured dental acrylic (Palavit G, Heraeus Kulzer, Wehrheim,Germany) in plastic cylinders to allow for standardized and secure placement during testing.

The specimens were stored in distilled water for 24 hours in $37^{\circ} \mathrm{C}$ before testing according to American dental association (ANSI/ADA) ${ }^{12}$ and International Organization for standardization (ISO) $)^{13}$ for direct filling resins and dental adhesion.

\section{Thermocycling}

All teeth were stored in water at $37^{\circ} \mathrm{C}$ for 24 hours before being subjected to thermocycling, 
and then subjected to thermocycling to simulate clinical thermal stress condition. The teeth were stored alternatively in water reservoirs at $5^{\circ} \mathrm{C}$ and $55^{\circ} \mathrm{C}$ respectively, remaining in each reservoir for 30 seconds. This procedure was carried out (500 cycles) for group A, B controlled by a computer.

\section{Shear bond Strength testing:}

Shear bond testing was measured on Lloyd universal testing machine (model LRX plus II. Fareham, England) using a wire loop applied under the gingival wings of thebracket, in order to induce gingival-oclusal shear stress at the adhesive interface.

Shear bond strength (SBS) tests were per-formed at a crosshead speed of $1 \mathrm{~mm} / \mathrm{min}$ and load cell of $1 \mathrm{kN}$, until failure occurred. Failure load values $\left(\mathrm{Kg} / \mathrm{Cm}^{2}\right)$ were recorded and converted into mega pascals $(\mathrm{MPa})$, dividing the failure load by the surface area of the bracket base.

The shear bond strength in $\mathrm{Kg} / \mathrm{Cm}^{2}$ was calculated from the equation:

$$
\sigma s=\mathrm{P} / \pi \cdot r^{2}
$$

Where:

$$
\begin{aligned}
& \text { os: shear bond strength in } \mathrm{Kg} / \mathrm{Cm}^{2} \\
& P \quad \text { is the shear load in } \mathrm{Kg} \\
& \pi=3.14 \\
& r \quad \text { is the radius of the specimen in } \mathrm{Cm}
\end{aligned}
$$

The shear bond strength was converted to $\mathrm{MPa}$ by multiplying the results by 0.09807 .

The loads at failure were recorded and the data were analyzed by one way analysis of variance (ANOVA) and Tukey's tests were used for testing the significance between the means of tested materials which statistically significant when the $P$ value $\leq 0.05$

\section{RESULT}

The result of this study showed that the comparison shear bond strength of orthodontic brackets between healthy and mild fluorosed enamel

The results of shear bond strength showed significant difference $(\mathrm{P}<0.05)$ between group $\mathrm{A}$ and group $\mathrm{B}$. The mean percentage for the ceramic brackets bonded to non-fluorosed enamel (healthy enamel (Group A) [11.25 MPa] while mean percentage for the ceramic brackets bonded to mild fluorosed enamel (Group B) [5.4 MPa].

TABLE (1) Comparison between mean shear bond strength in $(\mathrm{MPa})$ of orthodontic ceramic brackets between healthy and mild fluorosed enamel

\begin{tabular}{|c|c|c|c|c|}
\hline \multicolumn{2}{|c|}{ Group A } & \multicolumn{2}{c|}{ Group B } & \multirow{2}{*}{ P-value } \\
\cline { 1 - 4 } Mean & SD & Mean & SD & \\
\hline $11.25^{\mathrm{a}}$ & 0.46 & $5.4^{\mathrm{b}}$ & 0.75 & $0.000^{*}$ \\
\hline
\end{tabular}

* Significant at $P \leq 0.05$, Means with different letters are significantly different according to Tukey's test.

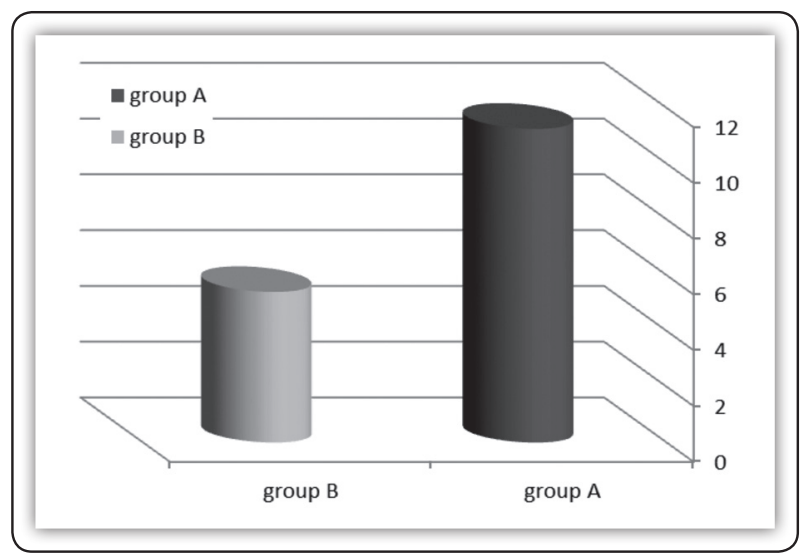

FIG (1) Bar chart of mean shear bond strength in (MPa) of the tested groups (group A and group B). 


\section{DISCUSSION}

Orthodontic brackets bonded to fluorosed teeth remains a difficult problem due to the lower solubility of fluoroapatite, present at high concentration in the external enamellayer ${ }^{14}$.

Enamel solubility is decreased due to presence of larger apatite crystals, better crystallinity, and buffering action of fluoride released by enamel crystals during initial stages of etching ${ }^{15}$.

The present study was to evaluate the influence of dental fluorosis on the shear bond strengths of orthodontic ceramic brackets bonded to enamel.

Shear bond strength test have been widely used, mainly because of their relative simplicity when compared to tensile bond strength test, in which it is difficult to align the specimen in the testing machine without creating deleterious stress distribution ${ }^{16,17}$.

Shear bond strength of orthodontic brackets of mild fluorosed enamel was lower value than healthy enamel. These results are in agreement with previousstudies ${ }^{18}$.

The mild fluorosis has lower enamel solubility, so some authors advocate the extension of etchingtime $^{19}$. It has been recommended to etch healthy teeth for 15-30 s, enamel with mild and moderate fluorosis for $30 \mathrm{~s}$, and etching enamel with severe fluorosis at least for 60-90 $\mathrm{s}^{20}$.

Etching tooth enamel with phosphoric acid creates surface microporosities and irregularities into which low-viscosity resins can readily flow. This formation of mechanical retention by cured resin on phosphoric acid-etched enamel has been the major factor responsible for the enamel adhesion of resin-based composite ${ }^{21}$.

The acid removes calcium salts from enamel, thus increases the size and number of micro spaces present in the enamel surface which is normally porous. When the resin is applied on such etched enamel surface, it can penetrate into micro spaces or irregularities, thus producing "resin tag" (finger like projections) with subsequent increase in bond strength and reduction of marginal staining and discoloration and it is the major factor responsible for the adhesion of dental resins to enamel ${ }^{22}$.

The adhesion achieved should be enough to withstand the stress produced in clinical situations, but extremely high bond values may induce enamel fractures during bracket debonding and increase the difficulty of the adhesive remnants removal, at the end of the treatment ${ }^{5}$. It has been suggested that obtaining bracket bond strength values ranging from 6 to $8 \mathrm{MPa}$ will be sufficient to ensure a good clinical performance and acceptable for routine clinic use as considered by Reynolds ${ }^{23}$, but not always we have an ideal situation for bonding brackets and the failure rate of brackets with Transbond plus range from $0.94 \%$ to $7.4 \%{ }^{24-26}$.

The fluorosed teeth have lower bond strength than non fluorosed teeth as mentioned above. It is known that several factors may influence the bond values, such as the mechanical test configurations used $^{27}$.

Further studies should be performed to evaluate the influence of different types of fluorosis, etching time and orthodontic adhesives on bracket bond strength, and to evaluate long-term durability of the bond. Clinical studies are also desirable.

\section{CONCLUSION}

The adhesion of Orthodontic brackets to enamel of the tooth is decreased by dental fluorosis.

\section{REFERENCE}

1. Beltrán E, Barker L, Dye B. Prevalence and severity of dental fluorosis in the United States, 1999-2004. NCHS Data Brief. 2010;53:1-8.

2. Denbesten P, Li W. Chronic fluoride toxicity: dental fluorosis. Monogr Oral Sci. 2011;22:81-96.

3. Waidyasekera K, Nikaido T, Weerasinghe D, Watanabe A, Ichinose S, Tay F, et al. Why does fluorosed dentine show a higher susceptibility for caries: an ultra-morphological explanation. J Med Dent Sci. 2010;57:17-23. 
4. Craig G: (2002) Restorative dental material $11^{\text {th }}$ edition. Mosby, Year Book Inc. St. Louis. USA. Chap.9: 231-57.

5. Silva E, Zavala-Alonso V, Martinez G, Loyola J, Patino N, Ortega I, et al. Shear bond strength evaluation of bonded molar tubes on fluorotic molars. Angle Orthod. 2013;83:152-7.

6. Ateyah N, Akpata E. Factor's affecting shear bond strength of composite resin to fluorosed human enamel. Oper Dent.2000;25:216-22.

7. Mandall N, Millett D, Mattick C, Hickman J, Worthington $\mathrm{H}$, Macfarlane T. Orthodontic adhesives: a systematic review. J Orthod. 2002;29:205-10.

8. Cheng Y, Zeiger D, Howarter J, Zhang X, Lin N, Antonucci J, et al: In situ formation of silver nanoparticles in photo crosslinking polymers. J Bio Mater Res 2011; 97:124-31.

9. Theodorakopoulou L, Sadowsky P, Jacobson A, Lacefield W. Evaluation of the bonding characteristics of 2 ceramic brackets: an in vivo study. Am J Orthod Dentofacial Orthop 2004;125:329-36.

10. Stanford S, Wozniak W, Fan P: The need for standardization of test protocols. Semin Orthod 1997; 3:206-09.

11. Littlewood S, Redhead A: Use of jigs to standardize orthodontic bond strength. J Dent 1998; 26:539-45.

12. American Dental Association Council on Scientific affairs (2002): American National Slandered\American Dental Association (ANSI\ADA) No.27: Dentistry-polymerbased filling restoration and lating material. P263-267.

13. International Organization for Standardization (ISO) (2001) mechanical specification 11405; Dental materials, testing of adhesion to tooth structure.

14. Torres I, Zavala V, Patino N, Martinez G, Anusavice K, Loyola J. Enamel roughness and depth profile after phosphoric acid etching of healthy and fluorotic enamel. Aust Dent J.2012;57:151-6.

15. Clarkson J, Hardwick K, Barmes D, Richardson L. International collaborative research on fluoride. J Dent Res.2000;79:893-4.

16. Kemp- Scholte C, Davidson C: Marginal sealing of curing contraction gaps in class $\mathrm{V}$ composite resin restorations. J Dent Res 1988, 67: 841-45.

17. Liu X, Han Y, Gao G, Li Z, Liu F. Effect of Silane Coupling Agent on the Mechanical, Thermal Properties and Morphology of Tremolite/PA1010 Composite. Chinese J Polymer Sci 2008; 26: 255-62.

18. Gungor A, Turkkahraman H, Adanir N, Alkis H. Effects of fluorosis and self-etching primers on shear bond strengths of orthodontic brackets. Eur J Dent. 2009;3:173-7.

19. Ateyah N, Akpata E. Factor's affecting shear bond strength of composite resin to fluorosed human enamel. Oper Dent.2000;25:216-22.

20. Johnston C, Burden D, Hussey D, Mitchell C. Bonding tomolars - the effect of etch time (an in vitro study). Eur J Orthod. 1998;20:195-9.

21. Hossam Z, Ola I, Inas E, Mohamed A, Ali I: Bond strength and morphological interface of self-etching adhesives to demineralized and remineralized enamel. J Dent Scie 2013; 8, 287-295

22. Rihito K, Tohru H, Kazutaka K: Bonding and debonding characteristics of orthodontic brackets to human enamel using modified 4-META/MMA-TBB resin. J orthodont wave 2007; 66:129-138.

23. Reynolds I: A review of direct orthodontic bonding. Br J Orthod $1975 ; 2: 171-8$

24. Pandis N, Eliades T. A comparative in vivo assessment of the long-term failure rate of 2 self-etching primers. Am J Orthod Dentofacial Orthop. 2005;128:96-98.

25. Aljubouri YD, Millett DT, Gilmour WH. Six and 12 months' evaluation of a self-etching primer versus twostage etch and prime for orthodontic bonding: a randomized clinical trial. Eur J Orthod. 2004;26:565-571.

26. Ireland AJ, Knight H, Sherriff M. An in vivo investigation into bond failure rates with a new self-etching primer system. Am J Orthod Dentofacial Orthop. 2003;124:323-326.

27. Klocke A, Kahl B. Effect of debonding force direction on orthodontic shear bond strength. Am J Orthod Dentofacial Orthop. 2006;129:261-5. 
